\title{
Caracterização das áreas hemófagas da placenta bovina ${ }^{1}$
}

\author{
Susana M.M. Cazerta² ${ }^{2}$ Maria Angélica Miglino ${ }^{3}$, Rodrigo S. Marques², Mirella \\ Vulcano $^{2}$ e Flávia T.V. Pereira ${ }^{2 *}$
}

\begin{abstract}
Cazerta S.M.M., Miglino M.A., Marques R.S., Vulcano M. \& Pereira FT.V. 2007. [Characterization of hemophagous areas of the bovine placenta.] Caracterização das áreas hemófagas da placenta bovina. Pesquisa Veterinária Brasileira 26(6):229-235. Faculdade de Zootecnia, Campus Dracena, Unesp, Rod. Com. João Ribeiro de Barros, SP294 Km 651, Dracena, SP 17900-000, Brazil. E-mail: fverechia@dracena.unesp.br

The specific region of maternal fetal interface needs to be clarified and corresponds to the "arcade zone" of sheep and goat placentomes. In small ruminants that area is also characterized by macroscopic blood extravasation (hemophagous areas). This occurs possibly because the iron is transferred to the embryo by trophoblastic erytrophagocytosis in these hemophagous placental areas. In order to investigate the hemophagous placental areas in cattle, placentomes of 34 pregnant Bos indicus cows (2-3, 4-6, 7-8 and 9 months of gestation) were analyzed. They were fixed by perfusion with $10 \%$ formaldehyde aqueous solution and $4 \%$ paraformoldehyde in PBS, pH 7.4, 0.1M, processed and stained for light microscopy and histochemistry. The methodology used allowed to observe placental haematomes between the uterine and trophoblastic epithelium since 3 months of pregnancy. Erythrocytes had been found in the trophoblastic cells, elucidating the erytrophagocytosis. Through Perl's histochemical reaction it was possible to prove the existence of ferric iron in the trophoblastic cells. The PAS reaction was positive staining mucoid substance in the epithelial cells, especially in the binucleate cells of the fetal epithelium. Based on histology and histochemistry, it can be inferred that the hemophagous areas are important sites for iron transfer in the bovine placenta.
\end{abstract}

INDEX TERMS: Erythrophagocytosis, hemophagous areas, bovine placenta, reproduction, trophoblast.

RESUMO.- A região específica da interface materno-fetal corresponde à zona arcada do placentônio ovino e caprino. Em pequenos ruminantes esta área é também caracterizada por sangue materno extravasado (áreas hemófagas). É possível que o ferro seja transferido para o feto por eritrofagocitose trofoblástica nestas áreas. Para investigar as áreas hemófagas na placenta bovina, foram analisados placentônios de 34 vacas zebuínas gestantes (dois a três, quatro a seis, sete a oito, e nove meses de prenhez). 0 material foi fixado com solução aquosa de formaldeído a $10 \%$ e paraformaldeído a 4\%, em tam-

\footnotetext{
${ }^{1}$ Recebido em 29 de janeiro de 2007.

Aceito para publicação em 29 de maio de 2207.

2 Faculdade de Zootecnia do Campus Dracena-UNESP, Dracena, SP 17900 000, Brasil. *Autor para correspondência: fverechia@dracena.unesp.br

3 Departamento de Cirurgia, Faculdade de Medicina Veterinária e Zootecnia da USP, Av. Prof. Dr. Orlando Marques de Paiva, 87, São Paulo, SP 05508-270, Brasil.
}

pão fosfato, $\mathrm{pH} 7,4,0,1 \mathrm{M}$, sendo processado e corado para microscopia de luz e histoquímica. Os hematomas placentários foram observados entre o epitélio uterino e trofoblástico, a partir de três meses de prenhez. A presença de eritrócitos nas células trofoblásticas elucidou a eritrofago-citose. A reação histoquímica de Perl's permitiu provar a existência de ferro férrico no trofoblasto. A reação de PAS foi po-sitiva, marcando substância mucóide nas células epiteliais e, principalmente, nas células binucleadas do epitélio fetal. Baseando-se nas características histológicas e histoquímicas, inferimos que as áreas hemófagas são sítios importantes para a transferência de ferro na placenta bovina.

TERMOS DE INDEXAÇÃO: Eritrofagocitose, áreas hemófagas, placenta bovina, reprodução, trofoblasto.

\section{INTRODUÇÃO}

A placenta das diversas espécies de animais representa o veículo para trocas de nutrientes entre a mãe e o feto. Esta fonte 
de nutrientes pode ser hemotrófica, ou seja, diretamente dos capilares maternos, ou histiotrófica, cuja nutrição ocorre a partir de secreções das glândulas uterinas ricas em enzimas, citocinas, fatores de crescimento, íons, tais como o ferro, hormônios, glicose, proteínas de transporte e moléculas de adesão (Gray et al. 2001a,b). Debris celulares do tecido endometrial e extravasamento de células sangüíneas podem, também, constituir-se em elementos intermediários na relação materno-fetal (Pereira 2004). Sabe-se que na interface materno-fetal de várias espécies (caninos, felinos, mustelídeos, ovinos, bovinos e bubalinos), ocorrem extravasamentos de sangue, os quais parecem possuir um aspecto celular diferenciado. Acredita-se que o feto utilize o ferro extravasado para sua própria hematopoiese. A função da eritrofagocitose, observada após o extravasamento de sangue na região do topo dos vilos maternos, é indefinida em várias espécies. Na ovelha, este processo foi muito estudado e ocorre na zona arcada do placentônio, região onde o processo é realizado pelo trofoblasto (Burton et al. 1976, Myagkaya \& Vreeling-Sindelarova 1976, Myagkaya et al. 1979, Myagkaya \& Schellens 1981, Myagkaya \& De Bruijn, 1982, King 1982, Myagkaya et al. 1984, Murai \& Yamauchi 1986, Santos et al. 1996). Vários estudos têm sido realizados, visando a esclarecer este mecanismo da passagem de ferro para o feto. Diversos autores têm demonstrado que a deficiência de ferro, durante a gestação em humanos e animais, resulta em problemas em longo prazo no recém-nascido, como, por exemplo, aumento na pressão sangüínea, diminuição na função cerebral e comprometimento do desenvolvimento do sistema imune (McArdle et al. 2003). Este trabalho teve como objetivo caracterizar, mediante métodos histológicos e histoquímicos, a região da interface materno-fetal de bovinos, contendo ou não as áreas hemófagas, bem como a eritrofagocitose placentária nestes animais.

\section{MATERIAL E MÉTODOS}

Foram utilizados placentônios de 34 vacas em diferentes fases da prenhez. 0 material foi distribuído em 4 grupos, de acordo com o tempo de gestação: Grupo 1 - 5 fêmeas com 60-90 dias de prenhez (2-3 meses); Grupo 2 - 15 fêmeas com 120-184 dias de prenhez (4-6 meses); Grupo 3 - 10 fêmeas com 210-240 dias de prenhez (7-8meses), e Grupo 4 - 4 fêmeas com 241-270 dias de prenhez (9 meses).

Imediatamente após o abate em frigoríficos, todos os animais tiveram a cavidade abdominal aberta para retirada do útero e seu conteúdo. A seguir, foi realizada uma incisão no sentido craniocaudal do cérvix uterino, em direção ao corno gestante. As membranas fetais foram abertas e o feto e os líquidos fetais removidos. As medidas cefalococcígeas dos fetos ( $\mathrm{CR}=$ Crown-Rump) foram tomadas para determinar a idade de prenhez, conforme as fórmulas estabelecidas por Richardson (1989). Os placentônios próximos ao feto foram isolados e fixados, com solução de parafolmaldeído a 4\% (Paraformoldehyde, Sigma Chemical Co., USA) e formaldeído a $10 \%$ em

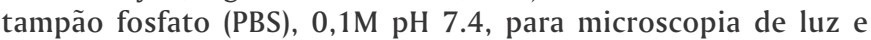
histoquímica. Fragmentos dos placentônios de aproximadamente $0,5 \mathrm{~cm}$ foram, então, reduzidos e imersos nesses fixadores por 24 horas. O material recebeu, então, os procedimentos da rotina histológica para inclusão em Histosec ${ }^{\circledR}$ (Merck). Cortes de 4 ou $5 \mu \mathrm{m}$ de espessura foram corados com hematoxilina e eosina (HE), Tricromo de Masson, Picrossírius, e submetidos às reações histoquímicas de
PAS contracoradas com hematoxilina de Harris, Perl's e fosfatase ácida, com posterior observação ao microscópio de luz Zeiss Axiostar Plus ${ }^{\circledR}$.

\section{RESULTADOS}

O placentônio constitui a união entre carúncula materna e cotilédone fetal, a unidade funcional da placenta. O cotilédone do bovino é constituído por numerosos vilos coriônicos delgados e ramificados. Esta ramificação aumenta com o avanço da prenhez, formando os vilos secundários e terciários, intensamente vascularizados, que se entremeiam nas criptas carunculares maternas. Cada vilo é formado por um eixo de mesênquima vascularizado, recoberto por células trofoblásticas (Fig. 1).

No período de 2-3 meses de prenhez o mesênquima mostrou-se abundante. Observou-se que o epitélio uterino era formado por uma única camada de células cúbicas com áreas de aspecto simplásmico (Fig.2a). Logo abaixo do epitélio o estroma endometrial distinguiu-se considerável quantidades de espessos feixes de fibras colágenas e vasos sanguíneos. Nos vilos fetais foi visualizada a reatividade positiva da reação de PAS, indicando a presença de material mucóide, principalmente, nas células trofoblásticas binucleadas, mas a reatividade não foi muito intensa nesta fase de prenhez.

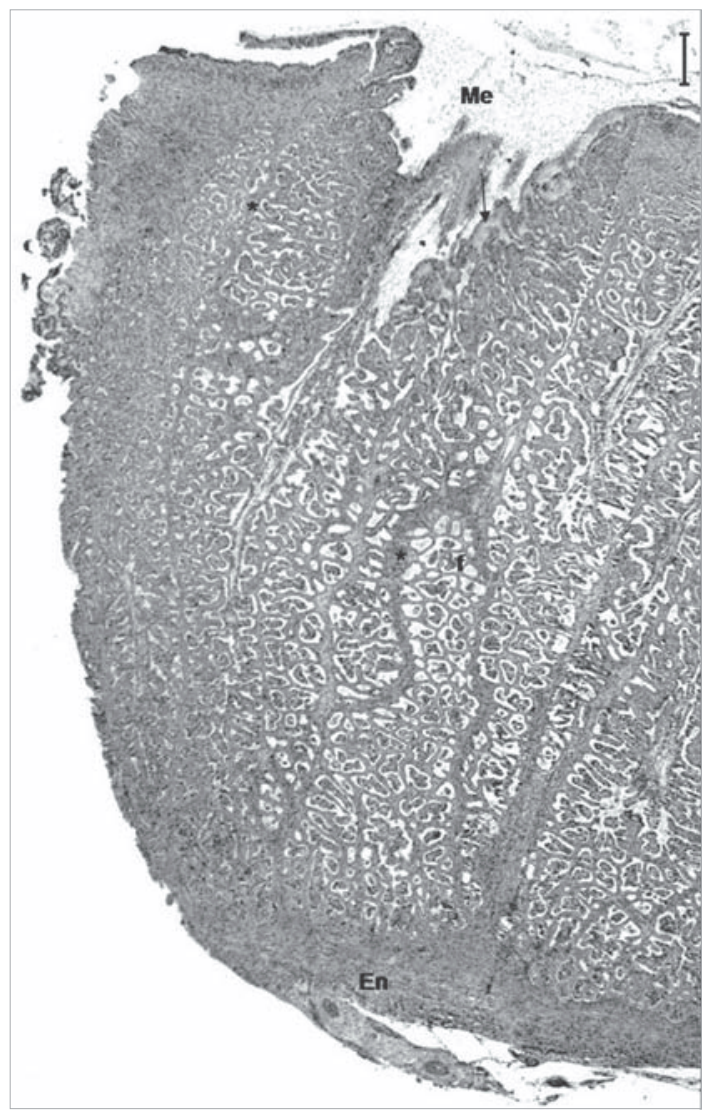

Fig.1. Junção materno fetal de um placentônio bovino aos 2 meses de gestação: mesênquima (Me), epitélio fetal (f), trofoblasto (seta), epitélio uterino (EU), estroma endometrial (*) e o endométrio (En). Histosec, HE. Barra $=300 \mathrm{~mm}$. 


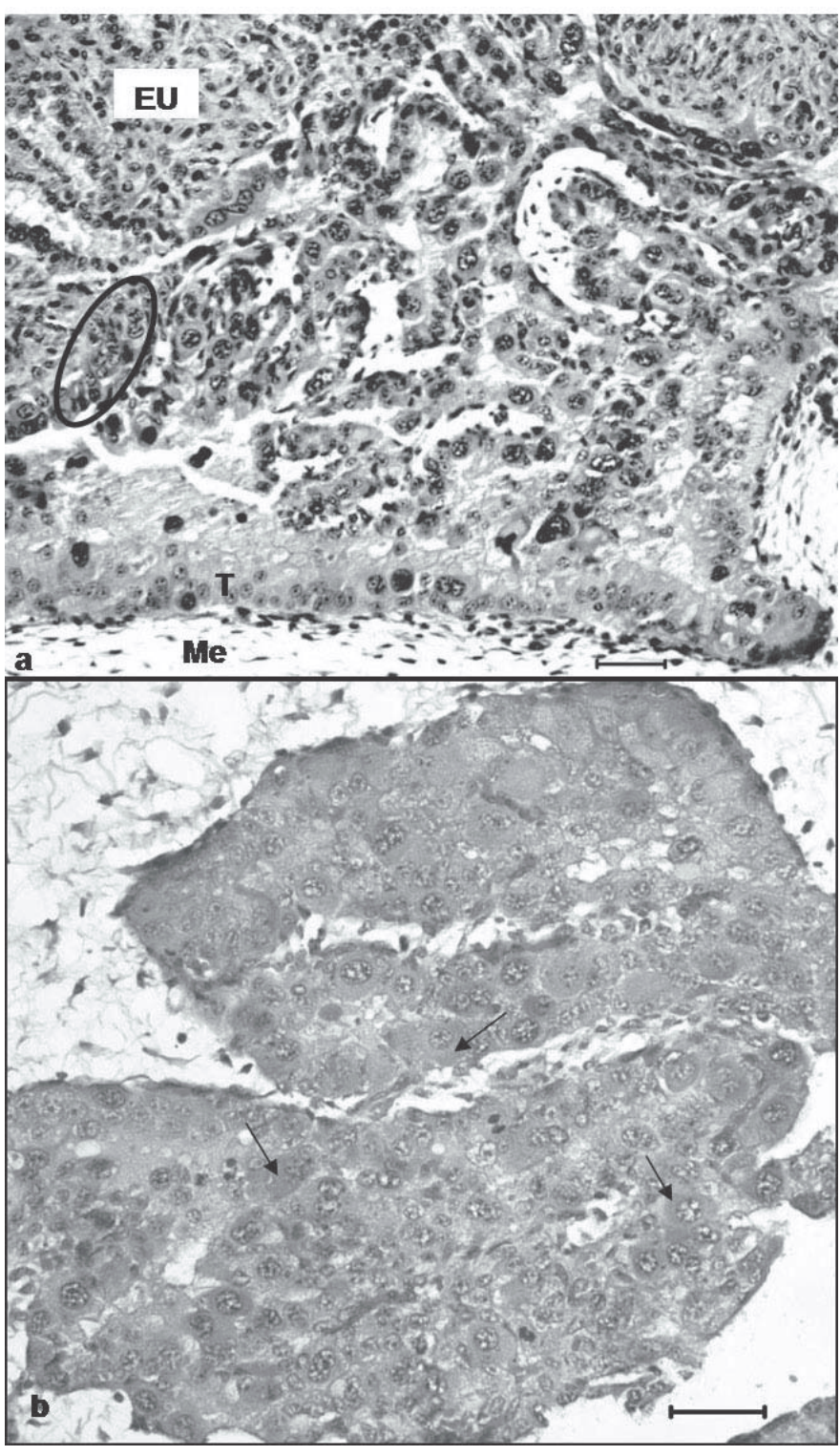

Fig.2. Junção materno fetal de placentônios bovinos aos 2-3 meses de gestação: a) Detalhe do mesênquima (Me), trofoblasto (T), epitélio uterino (EU) com áreas de aspecto simplásmico (elipse) e endométrio (En). Histosec, HE. Barra = 50ìm; b) Notar as setas indicando a reatividade positiva das células uni e binucleadas à reação de PAS. Histosec, PAS. Barra $=50 \mathrm{~mm}$.

No período de 4-6 meses de prenhez, o epitélio uterino não apresentou o aspecto simplásmico descrito anteriormente, sendo constituído por uma camada regular e uniforme de células epiteliais cúbicas. Observou-se, ocasionalmente nesta fase, as hematomas que se caracterizavam pelo acúmulo de sangue materno extravasado no interstício entre os epitélios uterino e trofoblástico (Fig.3a,b,c,d). Grande acúmulo de vesículas lipídicas e pigmentos hematógenos foram observados no citoplasma das células que margeavam o hematoma, estando ausente nas células das regiões mais afastadas da área hemófaga (Fig.4a,b). Os vasos sanguíneos fetais e maternos apresentaram-se em maior quantidade e mais próximos das estruturas epiteliais com que fazem contato. Nesta fase de prenhez a reação de PAS também foi positiva e marcou intensamente as células binucleadas, tanto na região que margeia o extravasamento de sangue quanto na região desprovida deste (Fig.4b).

No período de 7-8 meses de prenhez, extravasamento de sangue materno também esteve presente na interface materno-fetal. (Fig.5a,b,c,d). Seus aspectos gerais permaneceram semelhantes àqueles das outras fases estudadas, demonstrando somente variação morfológica microscópica. Ora elas encontravam-se esparramadas entre a interface materno-fetal, ora eram muito concentradas, aparecendo em pontos isolados na interface. Em algumas amostras, observou-se fibras colágenas na interface materno-fetal na região do hematoma (Fig.5a). As características gerais e estruturais observadas nesta fase de prenhez foram extremamente semelhantes às encontradas nas células que compõem a interface placentária aos 4-6 meses de prenhez, exceto por uma variação das células epiteliais maternas entre cúbicas e colunares e por uma maior abundância de pigmentos hematógenos presente no trofoblasto (Fig.5a,c). Nesta fase observamos a presença de eritrócitos no interior das células epiteliais do trofoblasto devido a sua eritrofagocitose, sugerindo uma possível transferência de ferro para o feto, porém o mesmo não foi observado nas células binucleadas (Fig.5b).

No período de 9 meses de prenhez áreas com hematomas, localizados na base dos vilos coriônicos, são freqüentes (Fig. 6a). Em algumas amostras, observou-se extravasa-mento de plasma no interstício entre os epitélios uterino e trofoblástico, com eritrofagocitose trofoblástica. A região do hematoma apresentava pigmentos hematógenos e vesículas nas células trofoblásticas (Fig.6e). A reação histoquímica de Perl's, para detectar a presença de ferro realizada nos placentônios, foi positiva na placenta de bovinos, principalmente na região de sangue materno extravasado (Fig.6b).

\section{DISCUSSÃO}

A interface materno-fetal de vacas apresentou, exceto aos dois meses de prenhez, áreas hemófagas localizadas entre o topo dos vilos maternos e a base dos vilos fetais, região correspondente à zona arcada da placenta de ovelhas e cabras, estudada por Wimsatt (1950), Lawn et al. (1969) e por Murai \& Yamauchi (1986) em vacas Bos taurus. Não identificamos dados referentes às áreas hemófagas em vacas zebuínas (Bos indicus).

As áreas hemófagas da placenta de vaca são achados ocasionais, isto é, não ocorrem em todos os placentônios e, consequientemente, em todas as lâminas analisadas sob microscopia de luz, fato este também descrito em vacas Bos taurus por Murai \& Yamauchi, (1986), e em búfalas por Pereira (2004).

A "zona arcada" da placenta de vacas, correspondendo à região do topo dos vilos maternos, que está em contato com a base dos vilos fetais, possui um epitélio modificado devido à presença de eritrócitos fagocitados dentro das células epiteliais trofoblásticas e, ainda, muitas vesículas lipídicas e pigmentos hematógenos. Estas estruturas estavam presentes em nossas amostras de placentas de vacas e também foram encontradas por Murai \& Yamauchi (1986), Mossman (1987), 


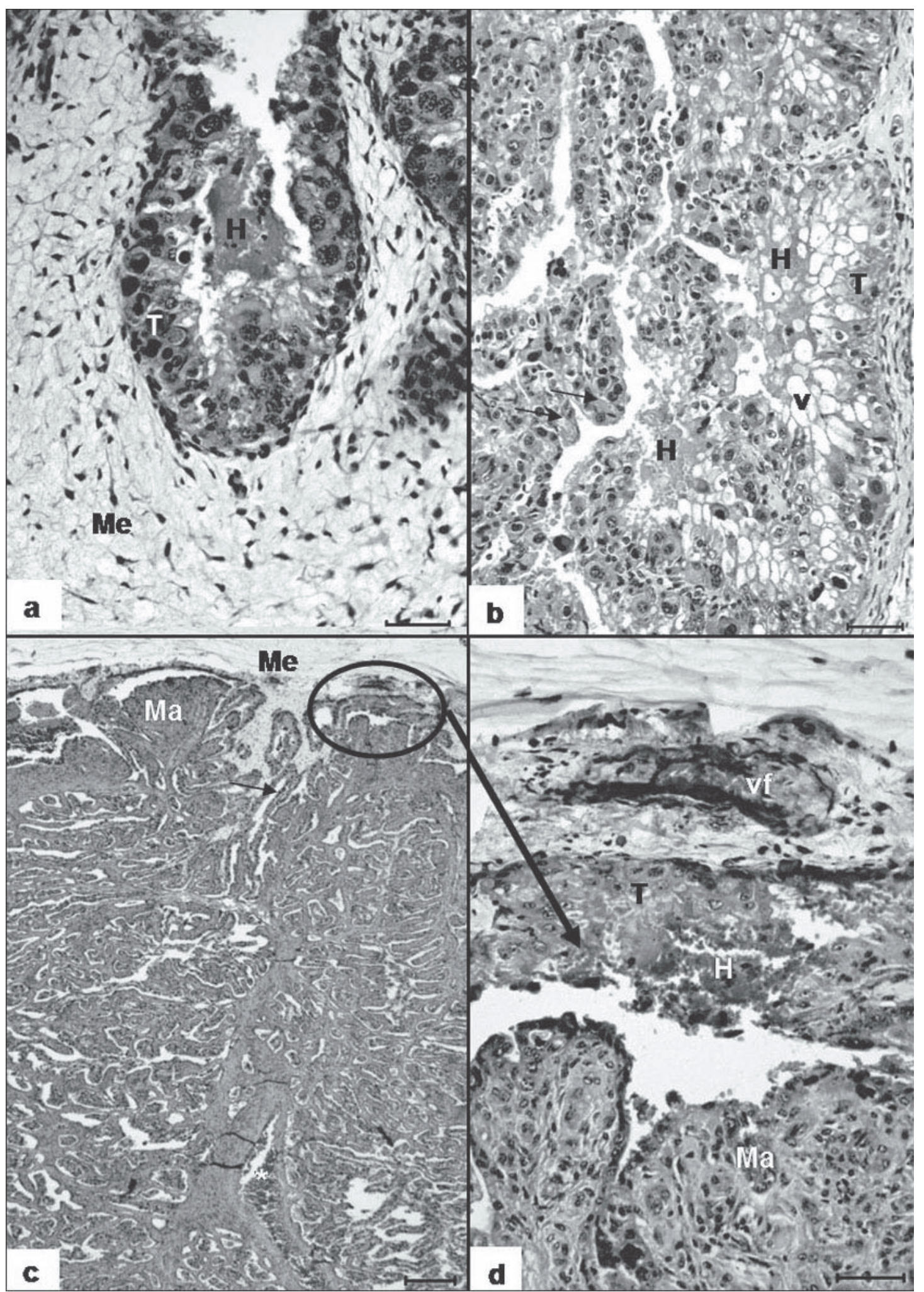

Fig.3. Junção materno fetal de placentônios bovinos: a) Detalhe do hematoma (H), trofoblasto (T) e do mesênquima abundante (Me); 4 meses de prenhez. Histosec, HE. Barra $=50 \mathrm{~mm}$; b) Notar as setas indicando a grande quantidade de vasos fetais (setas) e vesículas lipídicas (v) próximas ao trofoblasto $(\mathrm{T})$ que margeia o hematoma $(\mathrm{H}) ; 6$ meses de prenhez. Histosec, HE. Barra $=50 \mathrm{~mm}$; c) Vista geral da inferface materno-fetal: Mesênquima (Me), parte materna (Ma), vaso materno (*), vaso fetal (seta), região do hematoma (elipse e seta); 5 meses de prenhez. Histosec, HE. Barra $=300 \mu \mathrm{m}$; d) Detalhe da região do hematoma $(\mathrm{H})$, trofoblasto $(\mathrm{T})$, vaso fetal (vf), parte materna (Ma); 5 meses de prenhez. Histosec, HE. Barra $=50 \mu \mathrm{m}$. 


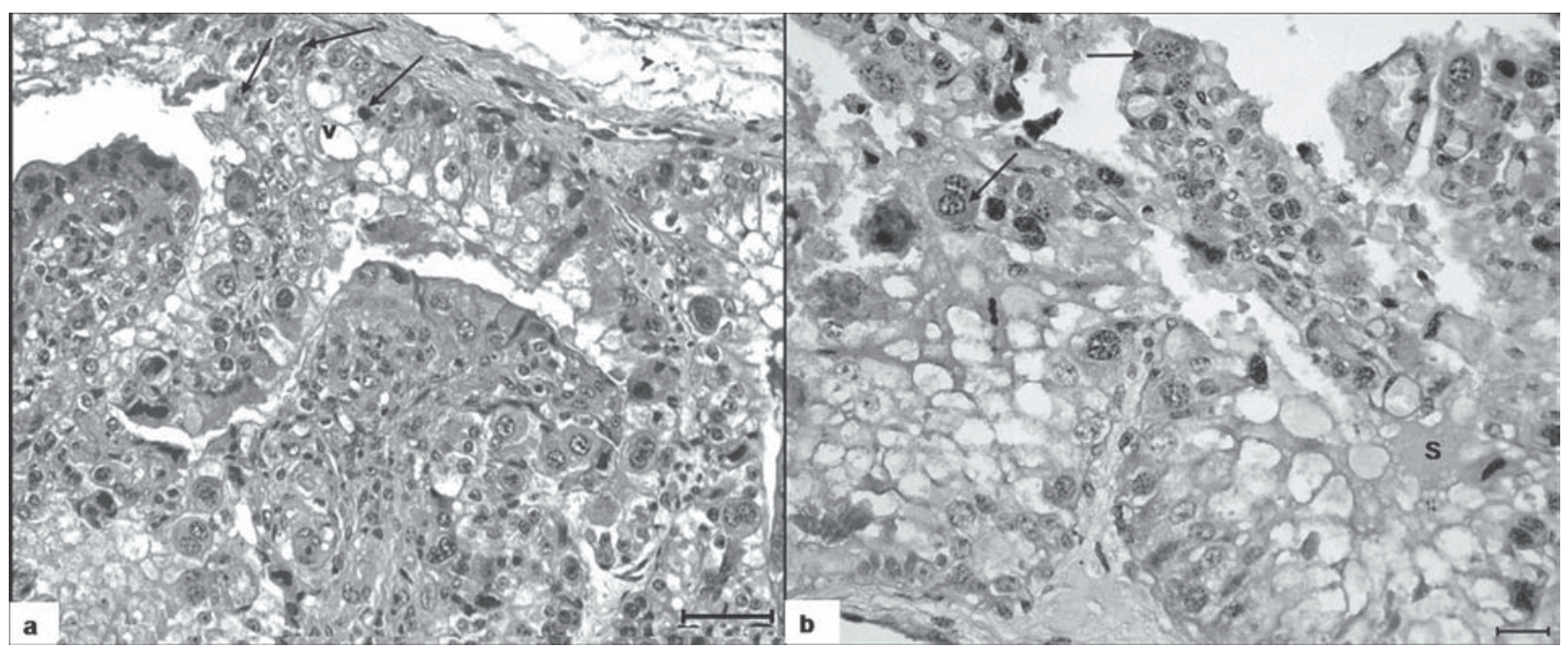

Fig.4. Junção materno fetal de placentônios bovinos aos 6 meses de gestação: a) Presença de pigmentos hematógenos no trofoblasto (setas) e vesículas lipídicas (v) próximas ao hematoma $(\mathrm{H})$. Histosec, $\mathrm{HE}$. Barra $=50 \mathrm{~mm}$; b) Detalhes da reatividade positiva das células binucleadas (setas) e no vilo fetal (S). Histosec, PAS. Barra $=20 \mathrm{~mm}$.

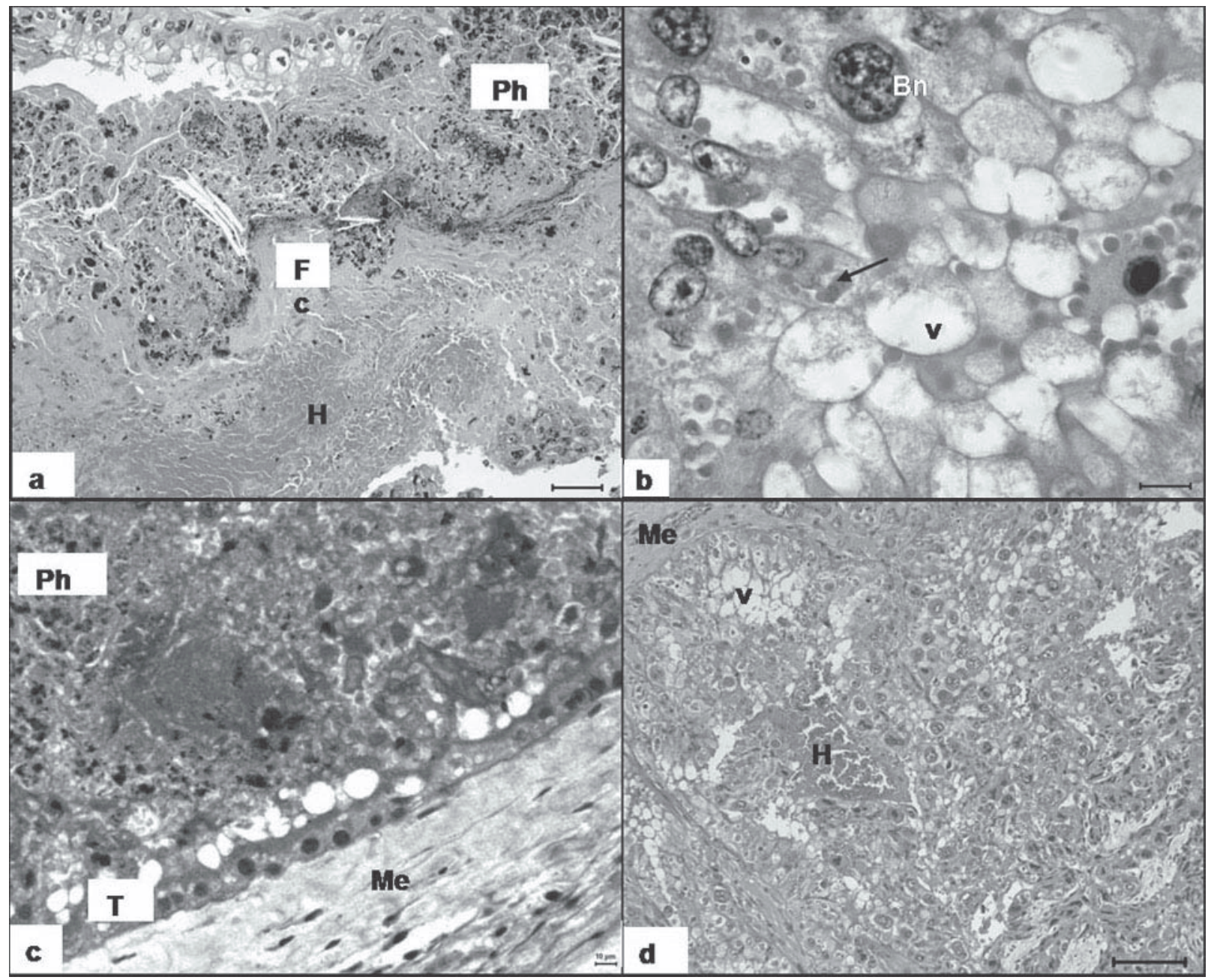

Fig.5. Junção materno fetal de placentônios bovinos aos 7-8 meses de gestação: a) Notam-se a morfologia diferente deste hematoma (H), presença de fibras colágenas $(\mathrm{F})$ e abundância de pigmentos hematógenos (Ph), trofoblasto $(\mathrm{T})$. Histosec, HE. Barra $=50 \mu \mathrm{m}$; b) Detalhe da hemácia fagocitada pelo trofoblasto (seta). Célula trofoblástica binucleada (Bn), vesícula (v). Histosec, HE. Barra $=10 \mu \mathrm{m}$; c) Observam-se a abundância de pigmentos hematógenos $(\mathrm{Ph})$ neste corte, trofoblasto $(\mathrm{T})$ e mesênquima (Me). Histosec, Picrossírius. Barra $=10 \mu \mathrm{m} ; \mathrm{d})$ Reação PAS positiva em uma área hemófaga $(\mathrm{H})$, mesênquima $(\mathrm{Me})$, vesículas $(\mathrm{v})$. Histosec, PAS. Barra $=100 \mu \mathrm{m}$. 


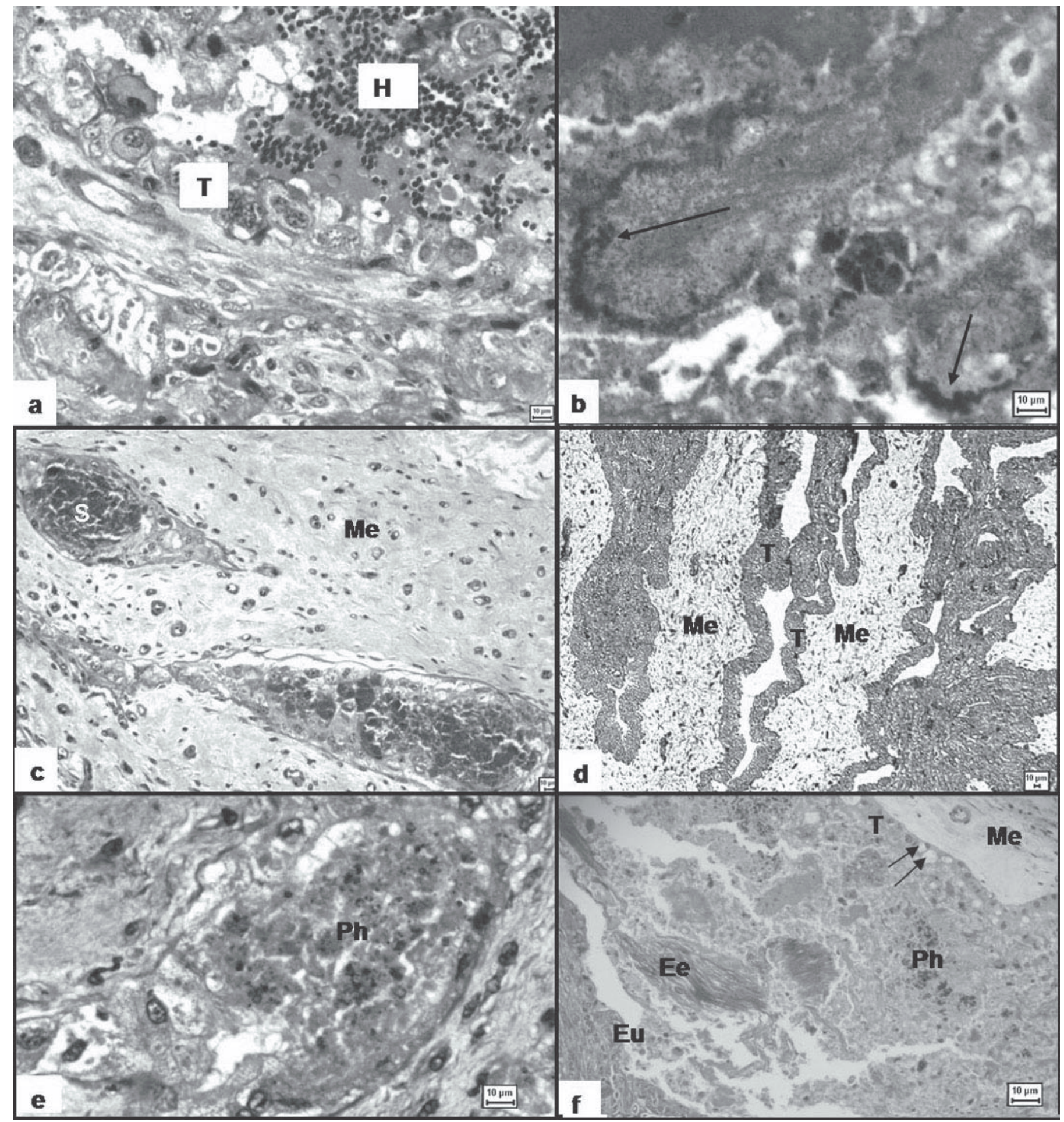

Fig.6. Placentônios bovinos aos 9 meses de gestação: a) Interface materno-fetal com área hemófaga (H) e trofoblasto (T). Histosec, Tricromo de Masson. Barra $=10 \mu \mathrm{m}$; b) Notar a coloração azulada (setas) produto da reação histoquímica de Perl's, a qual revela a reação positiva do trofoblasto para o ferro férrico. Histosec, Perl's. Barra $=10 \mu \mathrm{m}$; c) Detalhe de vilos fetais com secreções PAS positivas (S) e o mesênquima (Me) ricamente vascularizado; d) Reatividade positiva à fosfatase ácida (precipitados escuros), principalmente no mesênquima (Me). Trofoblasto (T). f) Notam-se a presença de fibras colágenas do estroma endometrial (Ee) na interface materno fetal, próximas à área hemófaga, pigmentos hematógenos ( $\mathrm{Ph}$ ), trofoblasto (T), mesênquima (Me), vesículas lipídicas (seta) epitélio uterino (Eu). Histosec, Picrossírius. Barra $=10 \mu \mathrm{m}$. 
Wimsatt (1950), Myagkaya et al. (1979), Leiser \& Egloff, (1990), Dantzer (1999) em Bos taurus, e em búfalas por Pereira (2004).

Enriquez-Yap (1974) e Wimsatt (1980) afirmaram que na placenta de ruminantes, as células epiteliais trofoblásticas e as células binucleadas participam do processo de fagocitose de eritrócitos maternos extravasados. Já nas amostras de placentas de vacas zebu somente as células epiteliais trofoblásticas participaram da fagocitose de eritrócitos maternos. Este fato corrobora com os relatos de Santos et al. (1996) e Pereira (2004).

Em algumas das amostras examinadas nesta investigação, observou-se presença de fibras colágenas na interface materno-fetal na região do hematoma, o que pode indicar remodelamento do estroma endometrial para atender às exigências do desenvolvimento fetal.

Vários autores sugeriram que as áreas hemófagas ou "hematomas" placentários possuem a importante função de transferência de ferro da mãe para o feto (Wimsatt 1950, Murai \& Yamauchi 1986, Latshaw 1987, Mossman 1987, Santos et al. 1996, Pereira 2004). Nas amostras de placentas de vacas zebu realizamos a reação de Perl's, que marca ferro férrico para observar a transferência de ferro transplacentário, e constatamos a presença de ferro no placentônio.

Este mesmo material, quando submetido à reação de PAS para detectar a presença de material mucóide, apresentou reatividade positiva em todas as fases estudadas, marcando com maior intensidade as células trofoblásticas binucleadas, em relação às células epiteliais trofoblásticas. Este fato sugere uma maior produção de hormônios placentários pelas células binucleadas, dado também constatado por Reimers et al. (1985), Pereira (2004) e Carvalho (2006).

A reação de fosfatase ácida na placenta de vacas zebu foi positiva somente na região do trofoblasto, fato este também observado em Bos taurus por Murai \& Yamauchi (1986).

O epitélio da "zona arcada” de bovinos é modificado, sugerindo propriedades secretórias, absortivas e fagocíticas que facilitam a nutrição fetal. Além disso, as áreas hemófagas da placenta bovina parecem ser importantes sítios de transferência de ferro, os quais podem estar envolvidos na hematopoiese fetal.

Agradecimentos.- Às Agências Financiadoras: Programa Institucional CNPq/ PIBIC/Unesp e Fapesp, à Faculdade de Zootecnia do Campus Experimental de Dracena, Unesp-Dracena, SP, e ao Departamento de Anatomia dos Animais Domésticos e Silvestres da FMVZ-USP, São Paulo, SP.

\section{REFERÊNCIAS}

Burton G.J., Samuel C.A. \& Steven D.H.1976. Ultrastructural studies of the placenta of the ewe: phagocytosis of erythrocytes by the chorionic epithelium at the central depression of the cotyledon. Q. J. Exp. Physiol. 61: $275-286$

Carvalho A.F., Klisch K., Miglino M.A., Pereira F.T. \& Bevilacqua E. 2006.
Binucleate trophoblast giant cells in the water buffalo (Bubalus bubalis) placenta. J. Morphol. 267(1):50-56.

Dantzer R.V. 1999. Epitheliochorial placentation, p.18-28. In: Knobil E. \& Neill J.D. (ed.), Encyclopedia of Reproduction. Academic Press, San Diego.

Enriquez-Yap E.L. 1974. The placentome of the philippine carabao (Bubalus bubalis) In mid-pregnancy: a study to establish the basis of clinicopathological analysis on the possible causes of early reproductive failures. Philipp. J. Vet. Med. 13(1-2):1-25.

Gray C.A., Taylor K.M., Ramsey W.S., Hill J.R., Bazer F.W., Bartol F.F. \& Spencer T.E. 2001a. Endometrial glands are required for preimplantation conceptus elongation and survival. Biol. Reprod. 64:1608-1613.

Gray C.A., Bartol F.F., Tarleton B.J., Wiley A.A., Johnson G.A., Bazer F.W. \& Spencer T.E. 2001b. Developmental biology of uterine glands. Biol. Reprod. 65:1311-1323.

King B.F. 1982. Comparative anatomy of placental barrier. Bibliotheca Anatomica (Karger, Basel) 22:13-28.

Latshaw W.K. 1987. Veterinary Developmental Anatomy: a clinically oriented approach. B.C. Becker, Toronto. 283p.

Lawn A.M., Chiquoine A.D. \& Amoroso E.C. 1969. The development of the placenta in the sheep and goat: an electron microscope study. J. Anat.105(3):557-578.

Leiser R. \& Egloff T. 1990. Ultrastructural correlates of placental substance transfer: a state-of-art-review. Placental Communications: biochemical, morphological and cellular aspects 199:219-238.

McArdle H.J., Danzeisen R., Fosset C. \& Gamblin G.L. 2003. The role of the placenta in iron transfer from mother to fetus and the relationship between iron status and fetal outcome. BioMetals 16:161-167.

Mossman H.W. 1987. Vertebrate fetal membranes. Rutgers University Press, New Brunswick. 383p.

Murai T. \& Yamauchi S. 1986. Erythrophagocytosis by the trophoblast in a bovine placentome. Jpn. J. Vet. Sci. 48 (1):74-87.

Myagkaya G. \& Vreeling-Sindelarova H. 1976. Erythrophagocytosis by cells of the trophoblastic epithelium in the sheep placenta in different stages of pregnancy. Acta Anat. 95:234-248.

Myagkaya G. \& Daems W.T. 1979. Fusion of erythrolysosomes in epitelial cells of the sheep placenta. Cell Tissue Res. 203:209-221.

Myagkaya G. \& Schellens J.P.M. 1981. Final stages of erythrophagocytosis in the sheep placenta. Cell Tissue Res. 214:501-518.

Myagkaya G.L. \& De Bruijn W.C. 1982. Ferritin in chorionic villi of the sheep placenta. Bibl. Anat. 22:117-122.

Myagkaya G., Schellens J.P.M. \& Vreeling-Sindelárová H. 1979. Lysossomal breakdown of erythrocytes in the sheep placenta. Cell Tissue Res. 197:79-94.

Myagkaya G.L., Schonargel K., Van Veen H. \& Everts V. 1984. Electron microscopic study of the localization of ferric iron in chorionic epithelium of the sheep placenta. Placenta 6(5):551-558.

Pereira FT.V. 2004. Eritrofagocitose placentária em búfalas (Bubalus bubalis bubalis Simpson, 1945). Tese de Doutorado, Faculdade de Medicina Veterinária e Zootecnia, USP, São Paulo. 102p.

Reimers T.J., Ullmann M.B. \& Hansel W. 1985. Progesterone and prostanoid production by bovine binucleate trophoblastic cells. Biol. Reprod. 33(5):1227-1236.

Santos R.L., Barreto Filho J.B., Marques Jr A.P. \& Andrade J.S. 1996. Erytrophagocytosis in the caprine trophoblast. Theriogenol. 46:1077-1083.

Wimsatt W.A. 1950. New histological observations on the placenta of the sheep. Am. J. Anat. 87:391-458. 